\title{
Engineered Trx2p industrial yeast strain protects glycolysis and fermentation proteins from oxidative carbonylation during biomass propagation
}

\author{
Rocío Gómez-Pastor ${ }^{2}$, Roberto Pérez-Torrado ${ }^{2}$, Elisa Cabiscol ${ }^{3}$, Joaquim Ros $^{3}$ and Emilia Matallana ${ }^{1,2^{*}}$
}

\begin{abstract}
Background: In the yeast biomass production process, protein carbonylation has severe adverse effects since it diminishes biomass yield and profitability of industrial production plants. However, this significant detriment of yeast performance can be alleviated by increasing thioredoxins levels. Thioredoxins are important antioxidant defenses implicated in many functions in cells, and their primordial functions include scavenging of reactive oxygen species that produce dramatic and irreversible alterations such as protein carbonylation.

Results: In this work we have found several proteins specifically protected by yeast Thioredoxin 2 (Trx2p). Bidimensional electrophoresis and carbonylated protein identification from TRX-deficient and TRX-overexpressing cells revealed that glycolysis and fermentation-related proteins are specific targets of Trx $2 p$ protection. Indeed, the TRX2 overexpressing strain presented increased activity of the central carbon metabolism enzymes. Interestingly, Trx2p specifically preserved alcohol dehydrogenase I (Adh1p) from carbonylation, decreased oligomer aggregates and increased its enzymatic activity.

Conclusions: The identified proteins suggest that the fermentative capacity detriment observed under industrial conditions in T73 wine commercial strain results from the oxidative carbonylation of specific glycolytic and fermentation enzymes. Indeed, increased thioredoxin levels enhance the performance of key fermentation enzymes such as Adh1p, which consequently increases fermentative capacity.
\end{abstract}

Keywords: Thioredoxins, Carbonylation, Yeasts, Biomass, Stress

\section{Background}

In the industrial yeast biomass propagation process, oxidative stress plays an important role by decreasing biomass yield and affecting fermentative properties of the produced biomass [1,2]. Studying oxidative stress during the biomass propagation process is essential to obtain stress-resistant yeasts that are able to complete the industrial process with no detriment of their fermentative and growth properties. Under industrial conditions, many cellular components are negatively affected since lipid peroxidation increases, while total glutathione and catalase activity decrease [3]. However, TRX2 gene overexpression improves Saccharomyces cerevisiae oxidative stress response by diminishing

\footnotetext{
* Correspondence: emilia.matallana@uv.es

'Departamento de Bioquímica y Biología Molecular, Universitat de València, Valencia, Spain

Full list of author information is available at the end of the article
}

the damage caused by ROS (reactive oxygen species) accumulation [3]. Trx2p is part of the cytosolic TRX system (thioredoxin1, thioredoxin 2, TRX reductase and NADPH) which reduces oxidized cysteine groups on proteins [4]. Thioredoxins act as reducing agents of the oxidized form of TRX peroxidase (TSA1), then favoring the action of reduced TRX peroxidase which scavenges ROS such as $\mathrm{H}_{2} \mathrm{O}_{2}$ [4]. Thioredoxins are involved in many cellular processes as a result of their oxidoreductase activity. They participate in sulphate metabolism by reducing PAPS enzyme (3'-phosphoadenosine 5'-phosphosulphate reductase) [5] and maintaining the dNTP synthesis rate during the S-phase by acting as an electron donor of ribonucleotide reductase [6]. Thioredoxins are also involved in protein folding, regulation of transcription factors [7] and protein repair after oxidative damage [8].

\section{Ciomed Central}


Thioredoxins regulate hydrogen peroxide-induced signaling pathways in yeast, like inactivation of Yap1p, the main oxidative AP-1-like transcription factor [8]. TRXs have also been implicated in the regulation of the redox state of $\mathrm{H}_{2} \mathrm{O}_{2}$-responsive signaling proteins, and they have many growth factor-like properties, including secretion, cell surface binding and catalytic activity [9]. In E. coli and plants, approximately 80 proteins have been associated with thioredoxins under different conditions, implicating thioredoxins in at least 26 cellular processes [10,11].

Damage caused by ROS accumulation includes oxidative alteration of cell components such as proteins, DNA and lipids. Under optimal physiological conditions, oxidative damage is minimized by antioxidant defenses that scavenge or prevent the generation of ROS, and repair or degrade oxidized molecules [12]. However under several stressful conditions, S. cerevisiae accumulates ROS, which oxidizes methionine residues, lowers the GSH/GSSG ratio and generates protein carbonylation $[13,14]$. Accumulation of protein-carbonyls groups by ROS is an important oxidative damage since it has been described as an irreversible modification, and it may function as a marker of oxidative stress, aging and age-related diseases $[15,16]$. Oxidatively modified proteins are generally dysfunctional, lose catalytic activity or structural integrity, and increase protein aggregates. Indeed, excessive carbonylation can cause crosslinked protein aggregates that are unable to be degraded by proteasome $[16,17]$. On the other hand, there are other oxidative modifications that are not necessarily negative, like S-thiolation, which is a reversible oxidative modification protecting proteins from carbonylation [18].

Increased levels of carbonylated proteins during aging and in response to oxidative stress are not random, and some proteins are more susceptible than others, especially those with a transition metal-binding site in their catalytic center [19]. Besides, selectivity of protein carbonylation is clearly demonstrated by the fact that the relative amount of each specific protein is not a determining factor in the degree of carbonylation [14]. However, this phenomenon is not well understood because some proteins exhibit a high carbonylation threshold without their catalytic function being affected [20].

We have previously demonstrated that $T R X 2$ overexpression is able to lower global carbonylation levels during bench top trials using $S$. cerevisiae industrial strains [3]. The molecular mechanism of protein protection from oxidative carbonylation by thioredoxins has not yet been demonstrated, although recent studies suggested that thioredoxins are implicated in the decarbonylation mechanisms of oxidized proteins [21]. Since cysteine residues are susceptible to being modified by carbonylation events [22], activity of thioredoxins as thiol-disulphide oxidoreductase and their participation in S-glutathionylation, the major form of S-thiolation [23], could play a key role in decreased carbonylation. Another suggested relationship between thioredoxins and oxidative carbonylation is the drop in Fe release from important proteins, like aconitase, as a result of diminished oxidative stress [24,25].

Other cellular antioxidant components, such as the methionine sulfoxide reductase A (MsrA), have been shown to be capable of preventing protein carbonylation in yeast and mice [26]. Moreover, there have been reports that calorie restriction lowers specific carbonylation in the proteins involved in glycolysis and chaperons by increasing superoxide dismutase and catalase activities and by extending lifespan [20]. Besides, experiments with yeast cells under aerobic conditions that are shifted to anoxia have revealed high carbonylation levels in glycolytic and mitochondrial proteins due to lack of oxygen [27]. This phenomenon could be associated with the transcription decrease of oxidative stress-related genes in anoxia, like the $T R X 2$ gene [2].

In the present work, we have identified different proteins whose implication in essential biological processes for yeast growth is relevant and which are specifically affected by oxidative carbonylation during biomass propagation. This work also contributes to the identification of new targets of thioredoxins that are protected against carbonylation damage. One example is Adh1p, which presents lowered carbonylation and reduced oligomer aggregation in a TRX2 overexpressing strain.

\section{Results}

\section{Oxidative damage increases in specific proteins during the biomass propagation process}

One of the most studied markers resulting from oxidative stress is protein carbonyl formation [14,28]. During wine yeast biomass propagation, cells are exposed to oxidative stress conditions at different critical time points [3,29]. Here we studied protein carbonylation during industrial propagation in yeast extracts by performing protein separation in 2D gels (additional file 1) and western blots anti DNP. Figure 1A provides three representative samples $(0 \mathrm{~h}, 15 \mathrm{~h}$ and $80 \mathrm{~h})$, showing increased protein damage during the process. At the starting time $(0 \mathrm{~h})$, just a few spots appeared to be carbonylated. During the diauxic shift (15 h), an increase in carbonylated spots was noted if compared to time $0 \mathrm{~h}$. At the end of the process, the number of carbonylated spots was similar to that obtained at $15 \mathrm{~h}$, but carbonyl intensity was greater. A total of 47 spots had been differentially carbonylated during biomass propagation and corresponded to 34 identified proteins (Table 1). Twenty-four proteins were identified by mass spectrometry and 10 proteins were identified by gel matching. The 34 identified proteins were grouped into six functional categories: glycolysis and fermentation, oxidative stress and mitochondrial metabolism, heat shock proteins, ATP metabolism, tricarboxylic acid cycle, and 


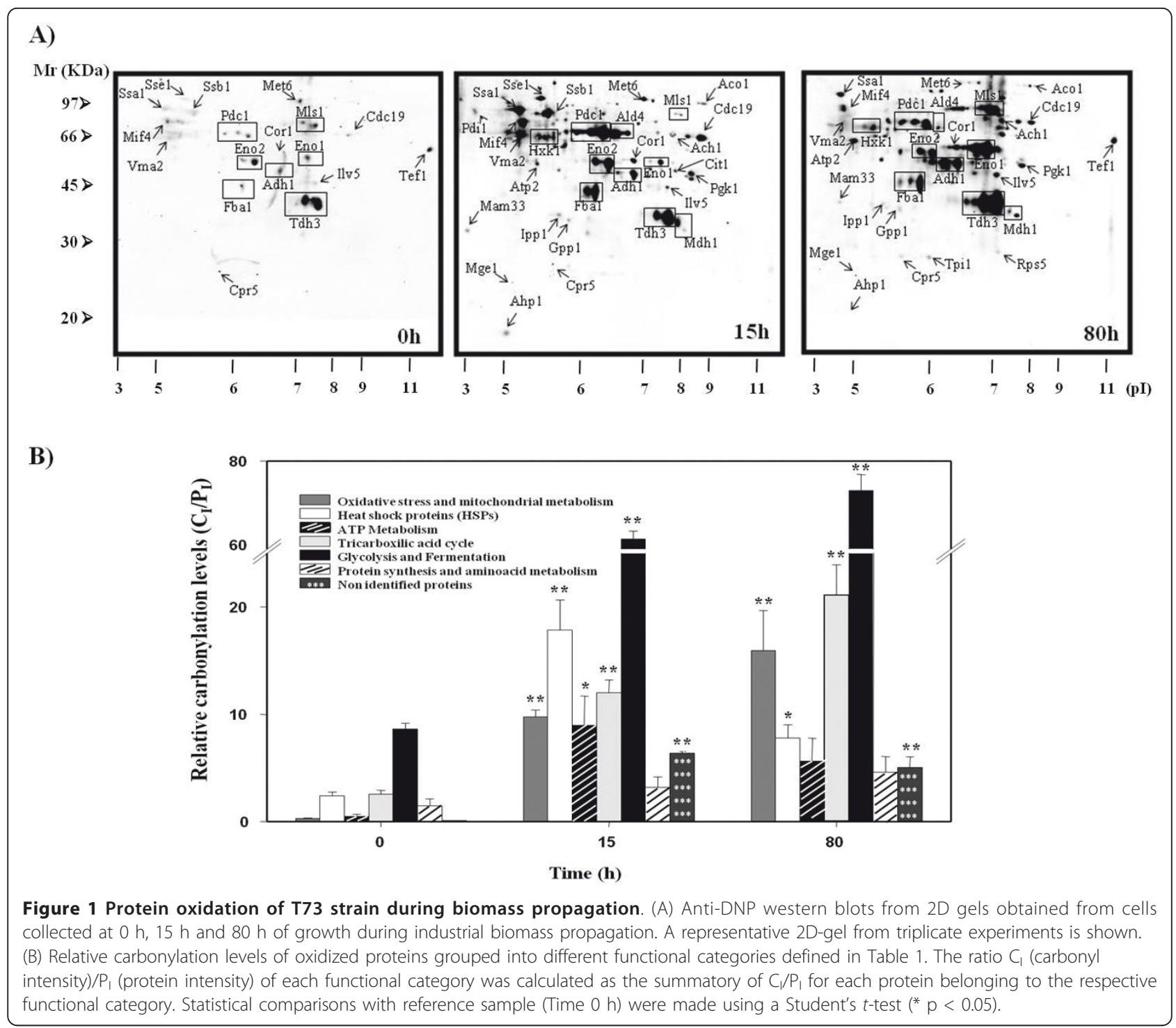

protein synthesis and amino acid metabolism. Figure 1B depicts the relative carbonylation levels for each functional category during industrial process. The most representative functional category was glycolysis and fermentation, which includes 12 specifically carbonylated proteins (Table 1). Key enzymes in fermentation processes such as Tdh3p, Eno1p and Adh1p were heavily damaged. The results show how the carbonylation of some proteins belonging to heat shock proteins (Mif4p and Ssa1p) and ATP metabolism (Vma1p and Atp2p) specifically increased at $15 \mathrm{~h}$ of growth, which lowered at the end of the process. On the other hand, the proteins grouped into oxidative stress and mitochondrial metabolism (Cor1p, Ilv5p), tricarboxylic acid cycle (Mls1p, Ach1p) and glycolysis and fermentation, presented significantly increased carbonylation levels at the end of the process.
The obtained carbonylation profiles correlate with those previously published by one-dimensional anti-DNP western blot [3], where a group of proteins showed peaked carbonylation during the industrial propagation process, whereas other proteins presented an accumulation of carbonyl content at the end.

\section{TRX2 overexpression protects proteins against oxidative carbonylation}

Little is known about the specific protein targets of thioredoxins in yeast. TRXs have been described to interact directly with Ahp1p, Tsa1p and Met16p when performing yeast two-hybrid knockout experiments [30]. However, their oxidoreductase activity can be extended to other protein not yet discovered. In order to identify possible targets in S. cerevisiae, we compared the oxidation level of 
Table 1 Carbonylated proteins during biomass propagation process for T73 wine yeast strain

\begin{tabular}{|c|c|c|c|c|c|}
\hline $\begin{array}{l}\text { Protein } \\
\text { name }\end{array}$ & Description & Molecular function & $\begin{array}{c}{ }^{\mathrm{a}} \mathrm{C}_{\mathrm{l}} / \mathrm{P}_{\mathrm{I}} \\
\text { Time } \\
\mathrm{O} \mathrm{h}\end{array}$ & 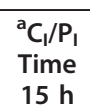 & 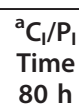 \\
\hline \multicolumn{6}{|c|}{ Oxidative stress and mitochondrial metabolism } \\
\hline$\| v 5 p$ & Acetohydroxyacid reductoisomerase & Mitochondrial DNA stability & 0.16 & 2.53 & 10.20 \\
\hline$\overline{\operatorname{Cor1}} \mathrm{p}$ & Ubiquinol-cytochrome c reductase (bc1 complex) & Electron transport chain & 0.03 & 2.28 & 3.89 \\
\hline Pdi1p & Protein disulfide isomerase & Formation of disulfide bonds & $\mathrm{Nd}$ & 2.44 & 0.12 \\
\hline Mam33p & Mitochondrial protein & Oxidative phosphorylation & $\mathrm{Nd}$ & 1.59 & 0.39 \\
\hline Ahp1 & Peroxiredoxin type ॥ & Oxidative damage protection & $\mathrm{Nd}$ & 0.91 & 0.22 \\
\hline \multicolumn{6}{|c|}{$\overline{\text { Heat }}$ shock proteins } \\
\hline Ssa1p & Heat shock protein 70 & Protein folding & 1.01 & 2.45 & 1.49 \\
\hline$\overline{\text { Mif4p }}$ & Heat shock protein 60 & Mitochondrial protein folding & 0.65 & 8.37 & 3.77 \\
\hline$\overline{S s b 1 p}$ & Cytoplasmic ATPase & Protein folding & 0.36 & 4.78 & 1.44 \\
\hline Sse1p & Heat shock protein 90 & Binds unfolded proteins & 0.06 & 2.30 & 1.20 \\
\hline Cpr5p & Peptidyl-prolyl-cis-trans isomerase & Response to unfolded proteins & 0.05 & 0.92 & 0.55 \\
\hline Mge1p & Mitochondrial co-chaperone & Folding of $\mathrm{Fe} / \mathrm{S}$ cluster proteins & $\mathrm{Nd}$ & 0.08 & 0.03 \\
\hline \multicolumn{6}{|c|}{ ATP Metabolism } \\
\hline Vma1p & Vacuolar H+ATPase & Vacuolar acidification & 0.40 & 4.08 & 0.71 \\
\hline Ipp1p & Inorganic pirophosphatase & Exchange of $\mathrm{O}_{2}$ from $\mathrm{Pi}$ with water & $\mathrm{Nd}$ & 1.96 & 0.86 \\
\hline$\overline{\text { ATp2p }}$ & ATP synthase ( $\beta$-sub F1) & ATP synthesis & $\mathrm{Nd}$ & 2.95 & 4.08 \\
\hline \multicolumn{6}{|c|}{$\overline{\text { Tricarboxilic acid cycle }}$} \\
\hline Mls1p & Malate synthase & Enzyme of the glyoxylate cycle & 0.73 & 0.62 & 9.07 \\
\hline Mdh1p & Malate dehydrogenase & Conversion malate and oxaloacetate & $\mathrm{Nd}$ & 2.23 & 1.03 \\
\hline Cit1p & Citrate synthase & $\begin{array}{l}\text { Condensation of acetyl coenzyme A and } \\
\text { oxaloacetate to form citrate }\end{array}$ & $\mathrm{Nd}$ & 1.35 & 0.67 \\
\hline Aco1p & Aconitase I & Tricarboxilic acid cycle & $\mathrm{Nd}$ & 1.23 & 1.36 \\
\hline Ach1p & CoA transferase & Acetate utilization & $\mathrm{Nd}$ & 0.98 & 4.08 \\
\hline \multicolumn{6}{|c|}{ 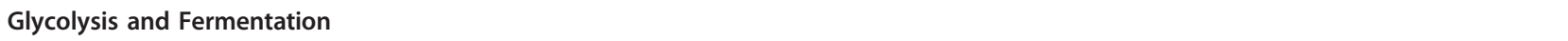 } \\
\hline Tdh3p & Glyceraldehyde-3-phosphate dehydrogenase & Glycolysis & 3.69 & 7.23 & 24.22 \\
\hline Eno1p & Enolase I & Glycolysis & 1.17 & 2.86 & 11.12 \\
\hline Adh1p & Alcohol dehydrogenase & Alcoholic fermentation & 0.94 & 4.67 & 8.32 \\
\hline Pdc1p & Piruvate dehydrogenase & Alcoholic fermentation & 0.53 & 13.21 & 4.48 \\
\hline Eno2p & Enolase ॥ & Glycolysis and Gluconeogenesis & 0.34 & 7.67 & 6.25 \\
\hline Fba1p & Fructose-1,6-bisphosphate aldolase & Glycolysis & 0.16 & 6.98 & 6.22 \\
\hline Cdc19p & Piruvate kinase & Glycolysis & 0.04 & 1.89 & 1.50 \\
\hline Ald $4 p$ & Aldehyde dehydrogenase & Required for growth on ethanol & $\mathrm{Nd}$ & 7.78 & 4.17 \\
\hline Hxk1p & Hexokinase & Glucose biosynthesis & $\mathrm{Nd}$ & 4.37 & 2.79 \\
\hline Gpp1p & DL-glycerol-3-phosphatase & Glycerol biosynthesis & $\mathrm{Nd}$ & 2.05 & 1.51 \\
\hline Pgk1p & 3-phosphoglycerate kinase & Glycolysis and Gluconeogenesis & $\mathrm{Nd}$ & 1.81 & 1.78 \\
\hline Tpi1p & Triose phosphate isomerase & Glycolysis & $\mathrm{Nd}$ & $\mathrm{Nd}$ & 3.21 \\
\hline \multicolumn{6}{|c|}{ Protein synthesis and amino acid metabolism } \\
\hline Tef1p & Translational elongation factor EF-1a & Binding of AA-tRNA to ribosomes & 1.36 & 0.85 & 1.15 \\
\hline Met6p & Methionine synthase & Methionine synthesis & 0.67 & 2.57 & 1.85 \\
\hline Rps5p & Protein component of the $40 \mathrm{~S}$ ribosome & Protein synthesis & $\mathrm{Nd}$ & $\mathrm{Nd}$ & 1.57 \\
\hline
\end{tabular}

${ }^{a}$ : Represented data correspond to $C_{1}$ (carbonyl intensity from western 2-D anti-DNP) normalized with $P_{1}$ (protein intensity) from 2-D gels (additional file 1). Underlined proteins were identified by mass spectrolmetry. Nd: no detected as carbonylated spots.

specifically carbonylated proteins in the T73 control strain during industrial biomass propagation with the oxidation levels obtained for the TRX2 gene-modified strains. Trx2p target proteins display lower oxidation levels when Trx2p overaccumulates, and higher levels when it is lacking. Figure 2 illustrates the western blot anti-DNP of 2D gels from the TTRX2 and trx 2 strains at $15 \mathrm{~h}$ and $80 \mathrm{~h}$ of growth during biomass propagation. The experiments were carried out in triplicate by performing 2-D gels in parallel with control strain T73. A total of 29 proteins were differentially carbonylated in both strains throughout the process (Table 2), and 22 proteins were identified by mass 


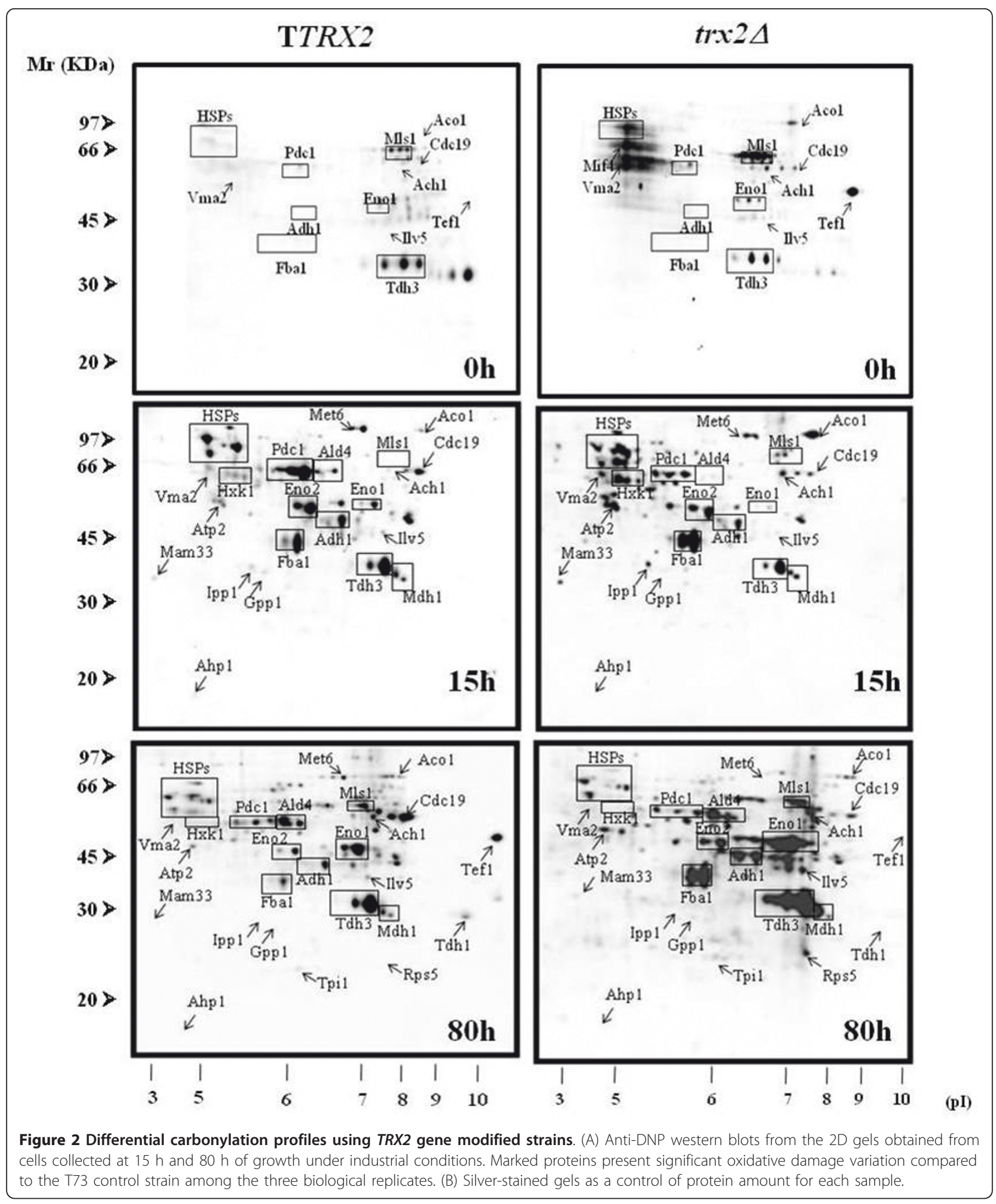

spectrometry. The relative carbonyl levels were analyzed as the ratio of carbonyl intensity of each protein and its corresponding protein intensity (additional file 2) when compared to the values obtained for the control strain. Ratio values of up to 1.5 fold increase or decrease if compared to the T73 strain were considered significant. At the starting point (time $0 \mathrm{~h}$ ) just few proteins were differentially carbonylated in TTRX2 and trx 2 strains comparing to control 
Table 2 Differentially carbonylated proteins in TRX2 gene modified strains along biomass propagation process

\begin{tabular}{|c|c|c|c|c|c|c|}
\hline \multirow[t]{2}{*}{ Protein name } & \multicolumn{2}{|c|}{ Time $0 \mathrm{~h}$} & \multicolumn{2}{|c|}{ Time $15 \mathrm{~h}$} & \multicolumn{2}{|c|}{ Time $80 \mathrm{~h}$} \\
\hline & TTRX2 vs T73 & trx2 vs T73 & TTRX2 vs T73 & Trx2 vs T73 & TTRX2 vs T73 & Trx2 vs T73 \\
\hline \multicolumn{7}{|c|}{ Oxidative stress and mitochondrial metabolism } \\
\hline$\underline{\| v 5^{*}}$ & Nv & Nv & $0.52(\downarrow)$ & $0.38(\downarrow \downarrow)$ & $0.45(\downarrow)$ & Nv \\
\hline Ahp1p & Nv & Nv & $0.23(\downarrow \downarrow)$ & $0.26(\downarrow \downarrow)$ & Nv & $\mathrm{Nv}$ \\
\hline \multicolumn{7}{|c|}{ Heat shock proteins } \\
\hline$\underline{\text { Ssa1p }}$ & Nv & $1.98(\uparrow)$ & 0.75 & 0.52 & 0.75 & Nv \\
\hline Mif4p* & $0.50(\downarrow)$ & $2.93(\uparrow)$ & $0.57(\downarrow)$ & $0.49(\downarrow)$ & $0.36(\downarrow)$ & Nv \\
\hline Ssb1 $1 p^{*}$ & $\mathrm{Nv}$ & Nv & 0.86 & $2.38(\uparrow)$ & 1.43 & $2.37(\uparrow)$ \\
\hline Sse1p* & 0.81 & 1.23 & $0.22(\downarrow \downarrow)$ & 0.87 & 1.38 & Nv \\
\hline Cpr5p & Nv & Nv & Nv & Nv & 0.82 & 0.85 \\
\hline \multicolumn{7}{|c|}{ ATP Metabolism } \\
\hline$\underline{\operatorname{Vam} 1 p^{*}}$ & 0.92 & $3.05(\uparrow \uparrow)$ & $0.15(\downarrow \downarrow)$ & $0.54(\downarrow)$ & $0.53(\downarrow)$ & 0.69 \\
\hline lpp1 $p^{*}$ & Nv & Nv & 0.65 & $2.24(\uparrow)$ & Nv & Nv \\
\hline Atp2p & Nv & Nv & $0.51(\downarrow)$ & $3.86(\uparrow \uparrow)$ & $0.37(\downarrow)$ & Nv \\
\hline Mam33p* & Nv & Nv & $0.48(\downarrow)$ & $2.13(\uparrow)$ & 0.86 & $1.72(\uparrow)$ \\
\hline \multicolumn{7}{|c|}{ Tricarboxilic acid cycle } \\
\hline Mls1p* & Nv & $2.03(\uparrow)$ & 0.75 & $1.79(\uparrow)$ & $0.11(\downarrow \downarrow)$ & 0.88 \\
\hline$\overline{M d h 1 p^{*}}$ & Nv & Nv & $1.68(\uparrow)$ & $2.01(\uparrow)$ & $\mathrm{NV}$ & $2.67(\uparrow)$ \\
\hline Acolp* & Nv & $1.53(\uparrow)$ & 0.86 & $4.03(\uparrow \uparrow)$ & 0.76 & $1.91(\uparrow)$ \\
\hline \multicolumn{7}{|c|}{ Glycolysis and Fermentation } \\
\hline Tdh3p* & 0.81 & 0.75 & 0.71 & 0.62 & $0.24(\downarrow \downarrow)$ & 2.38() \\
\hline Eno1p ${ }^{*}$ & Nv & Nv & $\mathrm{Nv}$ & $0.24(\downarrow \downarrow)$ & $0.32(\downarrow)$ & $3.61(\uparrow \uparrow)$ \\
\hline Adh1p* & Nv & Nv & 0.95 & 0.98 & $0.13(\downarrow \downarrow)$ & Nv \\
\hline Pdc1p & Nv & Nv & $0.56(\downarrow)$ & $0.45(\downarrow)$ & 0.65 & 0.64 \\
\hline Eno2p* & $0.46(\downarrow)$ & $0.53(\downarrow)$ & 0.85 & $0.52(\downarrow)$ & $0.29(\downarrow)$ & Nv \\
\hline$\underline{F b a 1 p^{*}}$ & Nv & Nv & $0.52(\downarrow)$ & $2.27(\uparrow)$ & $0.18(\downarrow \downarrow)$ & $4.07(\uparrow \uparrow)$ \\
\hline Cdc19p* & Nv & Nv & 0.79 & 0.60 & $2.76(\uparrow)$ & Nv \\
\hline Adl4p & Nv & Nv & $0.21(\downarrow \downarrow)$ & $0.15(\downarrow \downarrow)$ & $3.59(\uparrow \uparrow)$ & $4.28(\uparrow \uparrow)$ \\
\hline$\underline{\mathrm{H} x \mathrm{k} 1 \mathrm{p}^{*}}$ & Nv & Nv & $0.33(\downarrow)$ & $2.01(\uparrow)$ & $0.20(\downarrow \downarrow)$ & $0.27(\downarrow)$ \\
\hline Gpp1p & Nv & Nv & $0.53(\downarrow)$ & $0.41(\downarrow)$ & 0.85 & Nv \\
\hline Tpi1p & $\mathrm{NV}$ & $\mathrm{Nv}$ & Nv & Nv & 0.85 & 0.84 \\
\hline Tdh1p* & $1.53(\uparrow)$ & Nv & Nv & Nv & $1.84(\uparrow)$ & Nv \\
\hline \multicolumn{7}{|c|}{ Protein synthesis } \\
\hline Tef1p & $0.28(\downarrow \downarrow)$ & $1.92(\uparrow)$ & Nv & Nv & $1.82(\uparrow)$ & $0.12(\downarrow \downarrow)$ \\
\hline Met6p & $\mathrm{Nv}$ & Nv & Nv & Nv & $\mathrm{Nv}$ & 0.85 \\
\hline$\underline{\operatorname{Rps} 5 p^{*}}$ & Nv & Nv & Nv & Nv & Nv & $4.31(\uparrow \uparrow)$ \\
\hline
\end{tabular}

Represented data correspond to normalized Carbonyl intensity $\left(C_{1}\right)$ values from Western 2-D anti-DNP and Protein intensity $\left(P_{1}\right)$ from 2-D geles $($ Additional file 2) between the modified strain and control strains respectively. Ratios in bold character represent proteins with differential carbonylation pattern among TTRX2 and trx2 strains.

$(\uparrow)$ ratio [1.5-3]. $(\uparrow \uparrow)$ ratio $[>3],(\downarrow)[0.5-0.25] .(\downarrow \downarrow)$ ratio $[<0.25]$

Nv: No variation respect to carbonylation levels in T73 control strain.

* Putative targets of Trx $2 p$

strain T73, where heat shock proteins showed a significant increase in carbonylation level for trx2. The TTRX2 strain showed 13 proteins with a significant carbonylation level decrease at $15 \mathrm{~h}$ of growth, which were grouped into the six defined functional categories. These proteins include Ahp1p, Sse1p, Vma1p and Ald4p as the most down-carbonylated proteins. At the end of the process, when cells had been under respiratory conditions for more than $40 \mathrm{~h}$, we found 12 proteins with a significant carbonylation level decrease if compared to the control strain. The proteins with least oxidative damage were Hxk1p, Fba1p, Tdh3p and Adh1p, all of which are involved in glycolysis and fermentation, and were greatly damaged in the T73 strain.

Conversely, the $\operatorname{tr} x 2$ strain showed 12 proteins with reduced oxidative damage at $15 \mathrm{~h}$ of growth, some of which were similar to those founded in the TTRX2 strain. The fact that we found some proteins which presented a similar oxidative damage decrease among both modified 
strains could be associated with a compensatory phenomenon resulting from the lack of the TRX2 gene. However, the $\operatorname{tr} x 2$ strain presented 9 proteins which were more oxidized than the control strain, whereas Mam33p, Atp2p, Ipp1p, Aco1p, Hkx1p and Fba1p were less oxidized in TTRX2.

At $80 \mathrm{~h}$ of growth, the $\operatorname{tr} x 2$ strain showed 8 proteins which presented a higher carbonylation ratio, and 3 proteins with low carbonylation levels. Among the more oxidized proteins we found Rps5p, Fba1p, Eno1p and Ald4p. Besides, Mam33p, Aco1p and Fba1p were more oxidized in the trx 2 strain when compared to TTRX2 in both analyzed time samplings. In summary, the proteins with low oxidative damage levels in the TTRX2 strain or with high carbonylation levels in the trx 2 strain at any time point were putative thioredoxin targets. Based on these criteria, 22 proteins (Aco1p, Adh1p, Atp2p, Cdc19p, Eno1p, Eno2p, Fba1p, Hxk1p, Ilv5p, Ipp1p, Mam33p, Mdh1p, Mif4p, Mls1p, Rsp5, Ssa1p, Ssb1p, Sse1p, Tdh1p, Tdh3p, Tpilp, and Vma1p) were identified as presumable Trx2pprotected polypeptides.

Additional file 3 provides the different carbonylation profiles for each functional category at $15 \mathrm{~h}$ and $80 \mathrm{~h}$ of growth in the three T73, TTRX2 and trx 2 strains. The relative carbonylation levels of oxidative stress-related proteins presented significantly increased oxidative damage at the end of the process in the T73 and trx 2 strains (additional file 3 panel A). On the other hand, the TTRX2 strain displayed low carbonylation levels at both time points. Similar results were obtained for the proteins grouped in the functional tricarboxylic acid cycle (additional file 3 panel D) and glycolysis and fermentation categories (additional file 3 panel E). For the heat shock proteins (HSPs) (additional file 3 panel B), we observed a high oxidative damage level at the starting time of the process in T73 and $\operatorname{tr} x 2$, whereas it was lower for TTRX2. HSPs had reduced protein-carbonyls content at the end of the process in all the strains. However, TTRX2 presented once again the lowest carbonylation level. Regarding the proteins related to ATP metabolism (additional file 3 panel C), the trx 2 strain showed the highest oxidation levels at $15 \mathrm{~h}$ of growth. In contrast, TTRX2 had the lowest carbonylation levels at both time points. Finally, the proteins related to protein synthesis and amino acid metabolism (additional file 3 panel F) had similar carbonylation profiles in all the strains, except for an increase noted in the $\operatorname{tr} x 2$ strain at $80 \mathrm{~h}$.

\section{Oxidative carbonylation lowers glycolytic enzyme activities}

To check whether the increased carbonyl content in glycolytic proteins could affect their corresponding enzymatic function after industrial propagation, we analyzed the enzyme activities of ADH, PDC and ENO in the T73 and
TTRX2 strains. Catalase activity (CAT) was also assayed because it is a good marker of lowered enzyme activity when it undergoes oxidative carbonylation [20]. We inoculated the active dry biomass obtained at the end of the propagation process in YPGF medium to simulate fermentation conditions. Figure 3 shows the enzyme activity of $\mathrm{ADH}, \mathrm{PDC}, \mathrm{ENO}$ and CAT for the T73 and TTRX2 strains. TTRX2 displayed significantly higher ADH, PDC and CAT activities than the control strain correlating with the low carbonylation levels observed for the assayed enzymes. In correlation with these results, ENO and CAT activities decreased in trx 21.35 fold and 2.15 fold respectively (data not shown). Despite the large differences observed for Eno1p and Eno2p carbonyl content in TTRX2 compared to the control strain, no significant differences were observed in ENO enzymatic activity.

\section{TRX2 gene overexpression prevents Adh1 protein carbonylation and aggregates formation}

Adh1p, one of the most important enzymes in alcoholic fermentation, functions as a tetramer of four identical subunits of approximately $37 \mathrm{kDa}$ containing two zinc ions each. Adh1p was one of the most carbonylated proteins among glycolytic enzymes in T73 during biomass propagation experiments (Table 1). Besides, TTRX2 significantly reduced Adh1p protein oxidation and it was the least damaged protein compared to the control strain at the end of the process (Table 2). Thus, we wanted to study the Adh1p levels in the biomass production process but also in active dry yeast and in the same biomass inoculated in YPGF medium, where alcoholic fermentation occurs and Adh1p might have the most important role for the cell. We first analyzed global protein carbonylation under these conditions (additional file 4) and we observed that drying and YPGF re-inoculation also increased carbonyl levels after biomass propagation in T73 (1.71 fold and 2.35 fold respectively) whereas TTRX2 strain displayed lower carbonyl levels in all conditions (1.35 fold and 1.71 fold respectively). The reason for using cells in YPGF after $5 \mathrm{~h}$ of growth is to check if oxidized protein level changes under new fermentation conditions. However, we observed an additional increase in protein oxidation in YPGF medium especially for the control strain (additional file 4), which also correlated with the previous differences observed for fermentative capacity under these conditions between T73 and TTRX2 strains [31].

Figure 4 depicts the anti-Adh1p western blot experiments for the T73 and TTRX2 strains. The upper panel 4 A shows the anti-Adh1p western blot where three different bands can be observed in the T73 strain, corresponding to the monomer $(37 \mathrm{kDa})$, dimer $(74 \mathrm{kDa})$ and tetramer $(148$ $\mathrm{kDa}$ ) forms of Adh1p, and one additional band higher than $148 \mathrm{kDa}$, despite the western blot being performed under denaturing conditions. Unlike the control strain, TRX2 


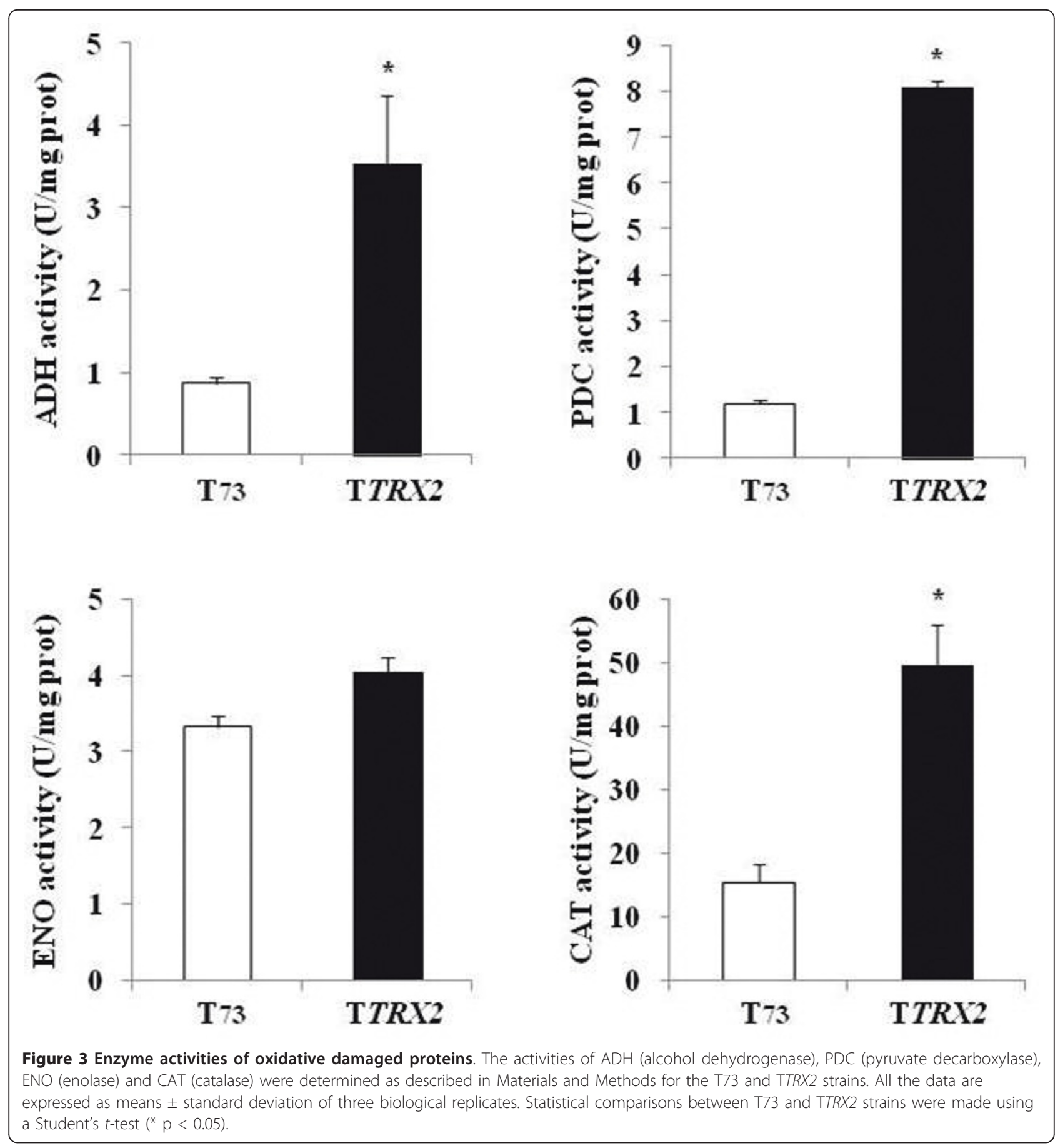

overexpressing cells showed Adh1p mainly in the monomer form. In addition, the amount of Adh1p monomer form in the T73 strain significantly decreased after growing in YPGF compared to dry yeast. However, the dimer and tetramer forms were still present under these conditions, suggesting an Adh1p monomer turnover due to its high oxidation level, whereas the other forms were not degraded. For the TTRX2 strain, the Adh1p amount in
YPGF slightly lowered, and neither the dimer nor the tetramer forms were observed.

In order to confirm that the different bands observed for Adh1p in the T73 strain are due to protein aggregates caused by carbonylation damage, we inoculated YPGF medium with fresh cells or cells treated with the carbonylation inductor glyoxal (GO) [32]. In Figure 4B we can observe for both strains that fresh yeast without 


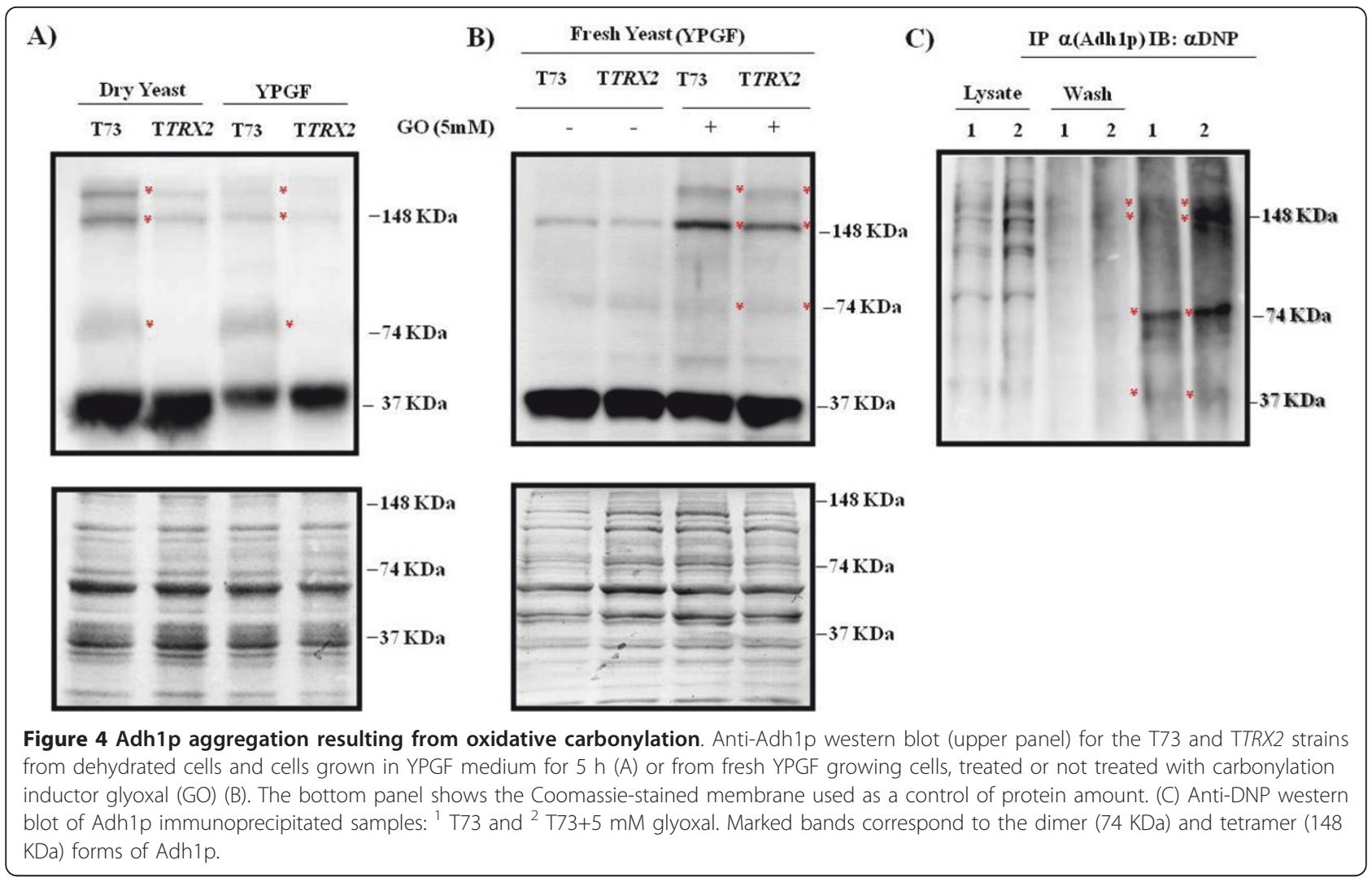

treatment mainly showed the monomer form and very slight bands corresponding to the dimer and tetramer forms. After treatment with GO, the band corresponding to the tetramer $(148 \mathrm{kDa})$ had increased and high weight forms appeared. Even under these induced conditions, the TTRX2 strain presented lower levels of tetrameric and high weight forms. To confirm that Adh1p aggregates were in fact carbonylated, Adh1p was immunoprecipitated and a subsequent western blot to detect carbonylation was performed (Figure 4C). The results confirm that high molecular weight Adh1p aggregates, corresponding to the size of dimers $(74 \mathrm{kDa})$, tetramers $(148 \mathrm{kDa})$, and higher oligomers, are indeed carbonylated. These results indicate that TRX2 overexpression increases Adh1p monomer stability by decreasing protein carbonylation and aggregates formation, thus maintaining its cellular concentration and increasing its enzyme activity.

\section{Discussion}

In this work, we have found that several proteins implicated mainly in glycolysis and fermentation become specifically carbonylated throughout industrial yeast biomass propagation, which affects their corresponding enzyme activities and lowers biomass fermentative capacity. This phenomenon can be directly related with the high oxidative stress which occurs at critical time points during the industrial process $[2,3]$. Under these conditions, we have previously observed improved biomass yield and fermentative capacity as a result of $T R X 2$ gene overexpression [3]. We have demonstrated that TRX2 gene overexpression is able to reduce oxidative damages, global protein carbonylation and lipid peroxidation levels, and to increase total glutathione and antioxidant enzyme activities. The aim of the present study was to identify those proteins that present increased carbonylation after industrial biomass propagation and to find putative Trx $2 \mathrm{p}$ protection targets that could highlight the improved phenotype of the TTRX2 strain [3].

From the western blot anti-DNP of 2D gels experiments using the T73 strain, we were able to identify selective protein carbonylation during the biomass propagation process. The main heat shock proteins Mif4p (Hsp60p), Ssa1p (Hsp70p) and Sse1p (Hsp90) become specifically carbonylated during the diauxic shift $(15 \mathrm{~h})$, as do the proteins relating with ATP metabolism. We obtained similar results for the oxidative stress-induced experiments by $\mathrm{H}_{2} \mathrm{O}_{2}$ [14] and by using chronologically aged cells [20]. These results suggest that oxidation of molecular chaperones may be due to their role as a proteins shield for ROS generated during the diauxic shift. Besides, another interesting oxidatively damaged protein 
at $15 \mathrm{~h}$ of growth is thioredoxin peroxidase Ahp1p, which uses thioredoxins as an electron donor and is highly implicated in the oxidative stress response [33]. By the end of the process, the carbonyl content of them all had lowered, but their protein levels either increased or did not vary [29]. Since carbonylation has been described as an irreversible process [15], the lower carbonyl content of these proteins can be explained by an effect of culture dilution as a consequence of biomass growth.

At the end of the propagation process, we observed that several proteins had been greatly damaged if compared to the initial growth steps. In this case, the proteins involved in glycolysis and fermentation, mitochondrial proteins (Cor5p and Ilv5p), and the proteins related to tricarboxylic acid cycle (Aco1p, Mls1p and Ach1p), all showed high carbonylation levels. We have previously demonstrated that cells grown under respiratory conditions (YPG medium) are better prepared to cope with oxidative stress than those grown under fermenting conditions (YPD medium), by reducing protein carbonyl content [34]. However, this work reveals that glycolytic enzymes undergo vast damage in the cells grown under respiratory conditions for a long period $(40 \mathrm{~h})$. Furthermore, there have been reports that prolonged cultivation of S. cerevisiae in aerobic, glucose-limited chemostat cultures progressively lowers glycolytic enzyme activities [35]. Among the most carbonylated glycolytic enzymes, we found Tdh3p (GAPDH), Enolp and Adh1p, which are key enzymes in alcoholic fermentation. Two of them (Tdh3p and Adh1p) catalyze oxidative reactions by using NADH. These enzymes' high carbonylation levels could be the main reason to explain the fermentative capacity detriment previously observed in the T73 strain $[2,3,36]$. In fact, GAPDH has been identified as a target of oxidative modification in many different cellular systems, which suggests its possible regulatory role as a sensor of oxidative stress conditions [37]. Krobitsch and colleagues [38] provided the first direct evidence for the oxidative inhibition of Tdh3p, and other glycolytic enzymes [39], in a controlled response that enables cells to redirect their carbohydrate flux from glycolysis to the pentose phosphate pathway, generating NADPH under stressful conditions. In addition, we have previously shown that $A D H 1$ gene overexpression increases the $\mathrm{NAD}^{+} / \mathrm{NADH}$ ratio, and increases chronological and replicative lifespan extension in S. cerevisiae by diminishing oxidative stress [40]. Thus, the Adh1p oxidative carbonylation and lowered $\mathrm{ADH}$ activity observed in the yeast propagation process may contribute to unbalance the $\mathrm{NAD}^{+} / \mathrm{NADH}$ ratio by enhancing oxidative stress.

It is interesting to note that most of the damaged proteins identified in our experiments undergo other oxidative modifications, especially at their cysteine residues [18]. Le Moan and colleagues [41] demonstrated that after $\mathrm{H}_{2} \mathrm{O}_{2}$ addition, the proteome of oxidized protein thiols of several stress chaperons and glycolytic enzymes depends exclusively on the thioredoxin functions controlling the activity of oxidized proteins. Besides, many of these proteins are also targets of S-glutathionylation, even in algae and mammal cells, suggesting an important role of the redox state in the regulation of the protein function for several organisms $[42,43]$.

The TRX2-overexpressing strain displays lower carbonylation levels for the majority of damaged proteins observed in wild-type strain, especially at the end of the industrial process. Most of these proteins also present cysteine residues close to the active site or important Cys disulfide bonds for their structure and catalytic function [41]. The increased Trx $2 p$ dosage (additional file 5) seems to stabilize the redox state of these cysteine residues by avoiding oxidative damage. As a result of less protein oxidative damage in the main glycolytic enzymes, TTRX2 strain exhibits greater GAPDH and ADH enzyme activities, suggesting a direct correlation between low carbonylation levels and great enzyme activity. The fact that the TTRX2 strain exhibits high levels of total glutathione during biomass propagation [3], and that several important proteins have lower carbonyl content, suggests that S-glutathionylation could protect against carbonylation. In addition, Tdh $3 p$ and Adh1p are susceptible to being modified by S-thiolation under $\mathrm{H}_{2} \mathrm{O}_{2}$ induced oxidative stress, which diminishes enzyme activity by at least 70\% [18]. Besides, it has been described that thioredoxins catalyze deglutathionylation in yeast by playing a key role in regulating the modification of proteins by the glutathione system [23]. The fact that the TTRX2 strain shows greater ADH and PDC activity after dehydration may also be associated with the fact that, under fermentative conditions, the deglutathionylation of both enzymes is higher than in the control strain as a result of TRX2 overexpression.

The improved fermentative capacity previously observed for the TTRX2 strain may be chiefly due to less oxidative damage in the aforementioned enzymes. In addition, increased alcohol dehydrogenase activity could also help reduce oxidative stress in this strain, and may be a reason for biomass yield improvement since $A D H 1$ gene overexpression increases yeast replicative and chronological lifespan $[3,40]$.

The comparison made between the TTRX2 and trx 2 strains allowed us to identify new targets of Trx $2 p$ protection. Most of these proteins are related to mitochondria, even Fba1p, which is involved in glycolysis, but localizes to the mitochondrial surface upon oxidative stress [44]. This suggests an implication of cytosolic thioredoxins in mitochondrial protein protection [45] under high endogenous oxidative stress conditions, as in the biomass production process.

One remarkable finding from this work is that Trx $2 p$ overexpression reduces Adh1p oligomers by the crosslinking caused by oxidative carbonylation. Although 
mild oxidation of a protein increases its degradation by proteasome 20S [45], excessive oxidation and cross-linking of proteins render them resistant to proteolytic degradation by the proteasome [18]. In E. coli, more than $95 \%$ of total carbonylated proteins are insoluble proteins mainly detectable in an aggregate state [46]. These authors proposed that some carbonylated proteins escape degradation in vivo by forming carbonylated protein aggregates, thus becoming non degradable which contributes to senescence. In several human neurodegenerative diseases it has been described how the proteins related to glycolysis and energy metabolism, cytoskeleton, chaperoning, cellular stress responses and members of the ubiquitin-proteasome system become aggregated as a result of oxidative damage [47]. According to these data, we suggest that $\operatorname{Trx} 2 \mathrm{p}$ is able to diminish protein carbonylation damage, thus preventing protein aggregates and oxidative damage expansion. The molecular mechanisms of Trx $2 \mathrm{p}$ protein protection against oxidative carbonylation could be associated with other oxidative modifications, especially at protein cysteine residues, and this phenomenon deserves further investigation.

\section{Conclusions}

In the present work, we have identified several proteins that are affected by oxidative carbonylation during yeast biomass propagation which are of relevant interest in fermentation processes. The identified proteins allowed us to conclude that oxidative carbonylation of the main glycolytic and fermentation enzymes is the most important reason for the fermentative capacity detriment observed under industrial conditions. Furthermore, higher thioredoxin levels enhance the performance of key fermentation enzymes such as Adh1p, and consequently increases fermentative capacity. Since the produced biomass needs to be of good quality, the results obtained for the TTRX2 strain suggest that improvement in the oxidative stress response during biomass propagation process is a good target for genetic and technologic manipulation.

\section{Materials and Methods}

\section{Strains, media and cultivation conditions}

We used S. cerevisiae strain T73 (CECT 1894) isolated from Alicante (Spain) musts [48], which is commercialized by Lallemand Inc. (Montreal, Canada). This strain has been widely used in several studies and has proven to be a good wine yeast model. This strain was previously genetically modified to T73ura3 [49] to construct other strains given the absence of auxotrophies in wine natural yeasts. These strains are also aneuploids, and have a chromosome number that is not a multiple of the haploid number, and they require several rounds of transformation for deletion gene construction.
The YEp-TRX2 plasmid was obtained by subcloning a $0.7 \mathrm{~kb} E c o R I$ fragment containing the yeast TRX2 gene and promoter in the episomal yeast plasmid Yep352 carrying selectable marker URA3. The TTRX2 strain [2] is a genetically-modified T73ura3 strain following the lithium acetate procedure as modified by [50].

Strain $\operatorname{trx} 2$ was obtained by sequential deletion of the two copies of the TRX2 gene in strain T73ura3. Disruption was carried out by homologous recombination at both ends of the TRX2 open reading frame of an integration cassette carrying a kanR marker gene flanked by loxP sites. Excision of the marker is inducible by the expression of Cre recombinase introduced into the same strain [51] to allow repeated disruptions. Integration of the cassette at the TRX2 locus and further excision of the kanR marker were confirmed by PCR analysis. The absence of any TRX2 gene product was confirmed by northern and western blot analyses. Uracil prototrophy was restored by introducing a 1.1-kb HindIII linear fragment containing the URA3 gene.

Precultures for industrial biomass propagation experiments were prepared in YPD liquid medium (1\% Yeast extract, $2 \%$ Peptone, $2 \%$ Glucose) and were incubated at $30^{\circ} \mathrm{C}$ with shaking $(250 \mathrm{rpm})$ for $12 \mathrm{~h}$.

Molasses medium (diluted to $60 \mathrm{~g}$ of sucrose $\mathrm{L}^{-1}$ for the batch phase or $100 \mathrm{~g}$ of sucrose $\mathrm{L}^{-1}$ for the fed-batch phase) was supplemented with $7.5 \mathrm{~g} \mathrm{~L}^{-1}$ of $\left(\mathrm{NH}_{4}\right)_{2} \mathrm{SO}_{4}, 3.5$ $\mathrm{g} \mathrm{L}^{-1}$ of $\mathrm{KH}_{2} \mathrm{PO}_{4}, 0.75 \mathrm{~g} \mathrm{~L}^{-1}$ of $\mathrm{MgSO}_{4} 7 \mathrm{H}_{2} \mathrm{O}, 10 \mathrm{ml} \mathrm{L}^{-1}$ of vitamin solution, and $1 \mathrm{ml} \mathrm{L}^{-1}$ of antifoam 204 (Sigma, St. Louis, Mo.). Molasses and mineral solutions were autoclaved separately. The vitamin solution containing 50 $\mathrm{mg} \mathrm{L}^{-1}$ of D-biotin, $1 \mathrm{~g} \mathrm{~L}^{-1}$ of calcium pantothenate, and $1 \mathrm{~g} \mathrm{~L}^{-1}$ of thiamine hydrochloride was filter sterilized $(0.2-\mu \mathrm{m}$ pore size) prior to use in the molasses medium.

The liquid medium YPGF (1\% Yeast extract, 2\% Peptone, $10 \%$ Glucose, 10\% Fructose) was used to inoculate fresh yeast and active dry yeast produced under industrial conditions to simulate must sugar content and wine fermentation conditions. YPGF medium was also supplemented with the carbonylation inductor glyoxal (GO) at $5 \mathrm{mM}$ for $1 \mathrm{~h}$ to induce protein carbonylation damage [32].

\section{Industrial production conditions}

Biomass propagation experiments were designed with two growth stages, batch and fed-batch, in a BIOFLO III bioreactor (NBS, New Jersey), and the technical parameters (agitation, $\mathrm{pH}$ and feed rate) were established as previously described $[1,3,29]$. Overnight YPD precultures were incubated at $30^{\circ} \mathrm{C}$ with shaking ( $\left.250 \mathrm{rpm}\right)$ (Time $0 \mathrm{~h}$ ). The bioreactor containing $2 \mathrm{~L}$ sterilized molasses medium at $\mathrm{pH} 4.5$ was then inoculated to an initial $\mathrm{OD}_{600 \mathrm{~nm}}$ of 0.05 . In the batch phase, cells consumed all the sucrose present in the medium using a fermentative metabolism. When 
sucrose was exhausted (12-15 h), cells changed their metabolism to respiration, allowing the consumption of the produced ethanol until approximately $40 \mathrm{~h}$ of the process. When ethanol was exhausted, the fed-batch phase started by feeding the reactor continuously with molasses medium at the desired flow rate until approximately $80 \mathrm{~h}$, thus avoiding fermentative metabolism in order to gain the highest biomass yield. Three independent production experiments were carried out for the T73, TTRX2 and trx2 strains.

\section{Biomass drying and rehydration}

At the end of the fed-batch fermentation, biomass was separated by centrifugation from the fermented media and subjected to several washing steps with distilled water. Concentrated biomass $(500 \mathrm{mg}$ ) was collected in petri plates. Yeast biomass was dehydrated under air flux in a convection oven at $30^{\circ} \mathrm{C}$ until approximately $8 \%$ relative humidity (approximately $24 \mathrm{~h}$ ) with opened petri plates [3]. Dehydrated biomass was collected in plastic bags and stored under vacuum conditions at room temperature during one week. Rehydration was performed in distilled water at $37^{\circ} \mathrm{C}$ during $10 \mathrm{~min}$ under static conditions and $10 \mathrm{~min}$ with shaking at $130 \mathrm{rpm}$ [52].

\section{Protein extraction and two-dimensional gel electrophoresis}

Cell samples $(25 \mathrm{mg}$ ) were collected at $0 \mathrm{~h}, 15 \mathrm{~h}$ and $80 \mathrm{~h}$ of growth for protein extraction. Cells were resuspended in $150 \mu \mathrm{L}$ extraction buffer (8 M Urea, $25 \mathrm{mM}$ Tris- $\mathrm{HCl}$ $\mathrm{pH} 8.0)$, a mixture of protease inhibitors (200 $\mu \mathrm{M}$ phenylmethylsulphonyl fluoride (PMSF), $20 \mu \mathrm{M}$ TPcK, $200 \mu \mathrm{M}$ pepstatin $\mathrm{A}$ ) and $0.2 \mathrm{~g}$ of glass beads. Cells were broken in Fast Prep (MP Bio) at $5.0 \mathrm{~m} / \mathrm{s}$ for $45 \mathrm{sec}$ on 3 occasions. After centrifugation at $12000 \mathrm{rpm}$ for $10 \mathrm{~min}$, the supernatant was sonicated and centrifuged again at $12000 \mathrm{rpm}$ for $10 \mathrm{~min}$. The protein concentration was determined with a Nanodrop ND-1000 UV/Vis spectrophotometer. Among 50-80 $\mu \mathrm{g}$ of protein were diluted in $340 \mu \mathrm{l}$ of Rehydration Buffer (8 M Urea, 4\% CHAPS (w/v), $50 \mathrm{mM}$ DTT and $0.5 \%$ ampholytes $(\mathrm{v} / \mathrm{v}) \mathrm{pH} 3-10$ (Amersham)). Isoelectric focusing (50-100 $\mu \mathrm{g}$ of protein) was performed in immobilised $\mathrm{pH}$ gradient strips (3-11 NL; Amersham). After the first dimension, strips were incubated for $20 \mathrm{~min}$ with $5 \mathrm{ml}$ of a solution containing $10 \mathrm{mM}$ 2,4-dinitrophenylhydrazine (DNPH) in 10\% trifluoroacetic acid (TFA). This compound reacts with carbonyl groups in proteins. To stop this reaction, the strip was transferred to a $5 \mathrm{ml}$ solution containing $0.4 \mathrm{M}$ Tris, $6 \mathrm{M}$ Urea, 2\% SDS and 20\% glycerol. Second dimension SDS-PAGE was performed on $18 \times 18 \mathrm{~cm} 11 \%$ polyacrylamide gels.

Four strips were run in parallel, two strips for the wild type and two strips for the respective mutant strain each time. Gels were either transferred to PVDF membranes for western blot analysis or silver strained and scanned in a GS800 densitometer (Bio-Rad). In both cases, obtained images were analyzed with the PDQuest software (BioRad). Gels were silver-stained using the PlusOne silver staining kit of General Electric Healthcare. PVDF membranes were silver-stained to control the protein load as described elsewhere [53].

\section{Western blot analysis and carbonyl content quantitation} Crude extracts were separated in 10\% SDS-polyacrylamide gels and transferred to the PVDF membrane from onedimensional gels. A polyclonal anti-Adh1p antibody was purchased from Acris (R1049) which is able to detect monomer, dimer and tetramer forms of Adh1p under SDS/PAGE conditions as described on the web site http:// www.acris-antibodies.com/antibodies/r1049.htm and diluted to 1:1000. The Western blots from two-dimensional gels were prepared as described in the previous section. A 1:5000 dilution of antibody against DNP (Dako) was used. In both cases, a peroxidase-conjugated anti-rabbit antibody was used for detection. Images were acquired in a ChemiDoc XRS System (Bio-Rad) and analyzed with the Quantity One software (Bio-Rad).

Carbonyl content was quantified using the PDQuest software (Bio-Rad). Carbonylation levels for each protein are calculated by dividing the carbonyl intensity from western 2-D anti DNP $\left(C_{I}\right)$ by protein intensity $\left(P_{I}\right)$ from 2-D silver-stained gels.

Protein identification by tryptic digestion and MALDI-TOF Protein spots were excised from gels and subjected to in situ digestion with trypsin on a ZipPlate (Millipore). Gel pieces were washed with $25 \mathrm{mM}$ ammonium bicarbonate and dehydrated with acetonitrile followed by (i) reduction of cysteines with $10 \mathrm{mM}$ DTT, (ii) alkylation of free cysteines with $55 \mathrm{mM}$ iodoacetamide, and (iii) in situ digestion with $170 \mathrm{ng}$ of trypsin overnight at $30^{\circ} \mathrm{C}$. Peptide extractions and washes were performed on a ZipPlate following the manufacturer's recommendations. Tryptic peptides were recovered in $5 \mathrm{ml}$ of $0.1 \%$ TFA, $50 \%$ acetonitrile, and spotted onto a MALDI plate in the presence of a-ciano-4-hydroxycynamic acid. Spectra were obtained in an Applied Biosystems voyager DE PRO MALDI-TOF apparatus operating in the reflector mode. The spectra with higher resolutions than 8000 were obtained. External calibration was performed with calibration mixtures from Applied Biosystems. The acquired spectra were processed by Data Explorer (version 4.0). Proteins were identified by peptide mass fingerprinting searching against the Swiss-Prot database using MASCOT. Protein coverage for each spot in the MASCOT analysis of up to 50 percent was considered significant. Alternatively, proteins were identified by gel matching with $S$. cerevisiae two-dimensional gel electrophoresis 
maps available in the following databases: YPD (Yeast Proteome Database; http://www.proteome.com); YMP (Yeast Mitochondrial Proteome; http://www.biochem. oulu.fi/proteomics/ymp.html); and 2-DE S. cerevisiae (IPG6-12) http://www.weihenstephan.de/proteomik/. Functional group analysis was performed using the GOstat and GO term finder (SGD database) online applications with a false discovery rate of $5 \%$. The represented data correspond to the average of three biological replicates.

\section{ADH immunoprecipitation}

Cells in IP buffer (50 mM Tris- $\mathrm{HCl}, \mathrm{pH} 7.5,150 \mathrm{mM}$ $\mathrm{NaCl}, 5$ mM EDTA, 10\% glycerol, 0.1\% Nonidet-P40) plus $1 \mathrm{X}$ protease inhibitors (Roche) and PMSF $0.4 \mathrm{mM}$ were broken with $0.5 \mathrm{~g}$ of glass beads in a Fast Prep (MP Bio) at $5.0 \mathrm{~m} / \mathrm{s}$ for $45 \mathrm{~s}, 3$ times. Lysates were clarified by centrifugation for $15 \mathrm{~min}$ at $14.000 \mathrm{rpm}$ and added to $20 \mu \mathrm{l}$ of Protein A/G PLUS-Agarose beads (Santa Cruz Biotechnology, INC) with bound polyclonal anti-ADH antibody (Acris antibodies). After a $4 \mathrm{~h}$ binding step at $4^{\circ} \mathrm{C}$, beads were washed three times with IP buffer plus $0.5 \%$ TritonX-100 and $0.5 \mathrm{mM} \mathrm{NaCl}$ and resuspended in carbonyl derivatization buffer ( $25 \mathrm{mM}$ Imidazol, $2 \mathrm{mM}$ EDTA, $\mathrm{pH}$ 7.0, 6\% SDS, 1X protease inhibitor) and boiled $3 \mathrm{~min}$. Sample proteins were derivatized with DNPH and separated in a 9\% acrylamide gel (BioRad Laboratories) and incubated with anti-DNP antibody at 1/3500 and anti-rabbit (1/5000).

\section{Enzyme activities}

Dehydrated cells were inoculated $\left(10^{7}\right.$ cells $\left./ \mathrm{mL}\right)$ in YPGF and incubated at $30^{\circ} \mathrm{C}$ and $65 \mathrm{rpm}$ for $5 \mathrm{~h}$. Samples were collected at the end of incubation, and cell extracts were prepared using glass beads and assayed as described in the following references: alcohol dehydrogenase [54], enolase [55], pyruvate decarboxylase [56] and catalase [57].

\section{Additional material}

Additional file 1: Two dimensional protein gels during biomass propagation at $0 \mathrm{~h}, 15 \mathrm{~h}$ and $80 \mathrm{~h}$ for control strain T73. Proteins were visualized with silver staining. The proteins whose intensity varied significantly $(P<0.05)$ among the three replicates for each time point were annotated on the gel.

Additional file 2: Two dimensional protein gels during biomass propagation at $0 \mathrm{~h}, 15 \mathrm{~h}$ and $80 \mathrm{~h}$ for $T R X 2$ gene modified strains. Proteins were visualized with silver staining and gels were used as loading control. The proteins whose intensity varied significantly $(P<$ 0.05) among the three replicates for each time point were annotated on the gel.

Additional file 3: Carbonylation profile of the different protein functional categories during biomass propagation process. Relative carbonyl content measured as $C_{1} / P_{1}$ of each defined functional category at $15 \mathrm{~h}$ and $80 \mathrm{~h}$ of growth among the three strains T73, TTRX2 and trx2. All the data are expressed as means \pm standard deviation. Comparisons among multiple groups were performed using the ANOVA ( $a$ is significantly different $(p<0.05)$ to $b$ and significantly different to $c(p<$ 0.05).

Additional file 4: Carbonyls levels after drying process and YPGF reinocculation. (A) anti-DNP monodimensional western blot at different time points of the industrial process and after drying and re-inocculation in YPGF for T73 and TTRX2 strains. (B) Relative carbonyl levels were quantified by using the QuantityOne software (Bio-Rad) and carbonylation levels were normalized with the protein amount.

Additional file 5: Trx2p visualization during biomass propagation. (A). Magnified regions of the two-dimensional gels where Trx2p can be observed in the different strains (A) T73 and (B) TTRX2 at $15 \mathrm{~h}$ of the biomass propagation process. (B) Western blot anti-Trx2p during biomass propagation. Coomassie-stained membranes are shown as a control of protein amount.

\section{Abbreviations}

ADH: Alcohol dehydrogenase; CAT: catalase; DNPH: 2,4-

dinitrophenylhydrazine; DNP: dinitrophenol; ENO: enolase; GSH: Reduced glutathione form; GSSG: Oxidized glutathione form; HRP: Horseradish peroxidase; OD: Optical density; PBS: Phosphate buffered saline; PDC: Pyruvate decarboxylase; PMSF: Phenylmethylsulfonyl fluoride; ROS: Radical oxygen species; SOD: Superoxide dismutase; TCA: Trichloroacetic acid; TPcK: $\mathrm{N}$-tosyl-L-phenylalanylchloromethyl ketone dinitrophenilhydrazine.

\section{Acknowledgements}

This work has been supported by grants AGL 2005-00508 and AGL 2008-00060 from the Spanish Ministry of Education and Science (MEC). R.G-P. was a predoctoral fellow of the I3P program from the CSIC (Spanish National Research Council). R.P-T. was a postdoctoral fellow of the JAEDOC program from the CSIC. We thank the Scientific-Technical Service of Proteomics and Genomics at the University of Lleida for their support in the proteomic analyses.

\section{Author details}

'Departamento de Bioquímica y Biología Molecular, Universitat de València, Valencia, Spain. ${ }^{2}$ Departamento de Biotecnología, Instituto de Agroquímica y Tecnología de Alimentos, CSIC, Apartado de Correos, 73. Burjassot (Valencia). E-46100, Spain. 'Departament de Ciències Mèdiques Bàsiques, IRBLleida, Universitat de Lleida, Spain.

\section{Authors' contributions}

RGP carried out most of the experiments and drafted the manuscript. RPT initiated the project, assisted with conception, data interpretation, statistical analyses and contributed to the writing of the manuscript. EC and JR assisted with the experimental design of the oxidative stress experiments. EM conceived the study, participated in its design, and contributed to the writing of the manuscript. All the authors have read and approved the final manuscript.

\section{Competing interests}

The authors declare that they have no competing interests.

Received: 27 September 2011 Accepted: 9 January 2012 Published: 9 January 2012

\section{References}

1. Perez-Torrado R, Bruno-Barcena JM, Matallana E: Monitoring stress-related genes during the process of biomass propagation of Saccharomyces cerevisiae strains used for wine making. Appl Environ Microbiol 2005, 71:6831-6837.

2. Perez-Torrado R, Gomez-Pastor R, Larsson C, Matallana E: Fermentative capacity of dry active wine yeast requires a specific oxidative stress response during industrial biomass growth. Appl Microbiol Biotechnol 2009, 81:951-960.

3. Gomez-Pastor R, Perez-Torrado R, Cabiscol E, Ros J, Matallana E: Reduction of oxidative cellular damage by overexpression of the thioredoxin TRX2 gene improves yield and quality of wine yeast dry active biomass. Microb Cell Fact 2010, 9:9. 
4. Herrero E, Ros J, Belli G, Cabiscol E: Redox control and oxidative stress in yeast cells. Biochim Biophys Acta 2008, 1780:1217-1235.

5. Muller EG: Thioredoxin deficiency in yeast prolongs $S$ phase and shortens the G1 interval of the cell cycle. J Biol Chem 1991, 266:9194-9202.

6. Koc A, Mathews CK, Wheeler LJ, Gross MK, Merrill GF: Thioredoxin is required for deoxyribonucleotide pool maintenance during $S$ phase. J Biol Chem 2006, 281:15058-15063.

7. Kuge $\mathrm{S}$, Jones $\mathrm{N}$ : YAP1 dependent activation of TRX2 is essential for the response of Saccharomyces cerevisiae to oxidative stress by hydroperoxides. EMBO J 1994, 13:655-664.

8. Izawa S, Maeda K, Sugiyama K, Mano J, Inoue Y, Kimura A: Thioredoxin deficiency causes the constitutive activation of Yap1, an AP-1-like transcription factor in Saccharomyces cerevisiae. J Biol Chem 1999, 274:28459-28465.

9. Yamawaki $\mathrm{H}$, Haendeler J, Berk BC: Thioredoxin: a key regulator of cardiovascular homeostasis. Circ Res 2003, 93:1029-1033.

10. Kumar JK, Tabor S, Richardson CC: Proteomic analysis of thioredoxintargeted proteins in Escherichia coli. Proc Natl Acad Sci USA 2004, 101:3759-3764.

11. Montrichard F, Alkhalfioui $F$, Yano $H$, Vensel WH, Hurkman WJ, Buchanan BB: Thioredoxin targets in plants: the first 30 years. $J$ Proteomics 2009, 72:452-474.

12. Moradas-Ferreira $P$, Costa V: Adaptive response of the yeast Saccharomyces cerevisiae to reactive oxygen species: defenses, damage and death. Redox Rep 2000, 5:277-285.

13. Perrone G, Dawes IW: Glutathione and catalase provide overlapping defenses for protection against hydrogen peroxide in the yeast Saccharomyces cerevisiae. Biochem Biophys Res Commun 1998, 253:893-898.

14. Cabiscol E, Piulats E, Echave P, Herrero E, Ros J: Oxidative stress promotes specific protein damage in Saccharomyces cerevisiae. J Biol Chem 2000, 275:27393-27398.

15. Stadtman ER: Protein oxidation and aging. Science 1992, 257:1220-1224.

16. Dalle-Donne I, Aldini G, Carini M, Colombo R, Rossi R, Milzani A: Protein carbonylation, cellular dysfunction, and disease progression. J Cell $\mathrm{Mol}$ Med 2006, 10:389-406.

17. Grune $T$, Jung T, Merker K, Davies KJ: Decreased proteolysis caused by protein aggregates, inclusion bodies, plaques, lipofuscin, ceroid, and 'aggresomes' during oxidative stress, aging, and disease. Int J Biochem Cell Biol 2004, 36:2519-2530.

18. Shenton D, Grant CM: Protein S-thiolation targets glycolysis and protein synthesis in response to oxidative stress in the yeast Saccharomyces cerevisiae. Biochem J 2003, 374:513-519.

19. Stadtman ER: Metal ion-catalyzed oxidation of proteins: biochemical mechanism and biological consequences. Free Radic Biol Med 1990, 9:315-325.

20. Reverter-Branch, Cabiscol E, Tamarit J, Ros J: Oxidative damage to specific proteins in replicative and chronological-aged Saccharomyces cerevisiae: common targets and prevention by calorie restriction. J Biol Chem 2004, 279:31983-31989.

21. Wong CM, Cheema AK, Zhang L, Suzuki YJ: Protein carbonylation as a novel mechanism in redox signaling. Circ Res 2008, 102:310-318.

22. Salsbury FR Jr, Knutson ST, Poole LB, Fetrow JS: Functional site profiling and electrostatic analysis of cysteines modifiable to cysteine sulfenic acid. Protein Sci 2008, 17:299-312.

23. Greetham D, Vickerstaff J, Shenton D, Perrone GG, Dawes IW, Grant CM: Thioredoxins function as deglutathionylase enzymes in the yeast Saccharomyces cerevisiae. BMC Biochem 2010, 11:3.

24. Pierre $\mathrm{L}$, Fontecave $\mathrm{M}$ : Iron and activated oxygen species in biology: the basic chemistry. Biometals 1999, 12:195-199.

25. Cantu D, Schaack J, Patel M: Oxidative inactivation of mitochondrial aconitase results in iron and $\mathrm{H} 2 \mathrm{O} 2$-mediated neurotoxicity in rat primary mesencephalic cultures. PLoS One 2009, 4:e7095.

26. Moskovitz J, Oien DB: Protein carbonyl and the methionine sulfoxide reductase system. Antioxid Redox Signal 2010, 12:405-415.

27. Dirmeier R, O'Brien KM, Engle M, Dodd A, Spears E, Poyton RO: Exposure of yeast cells to anoxia induces transient oxidative stress. Implications for the induction of hypoxic genes. J Biol Chem 2002, 277:34773-34784.

28. Costa VM, Amorim MA, Quintanilha A, Moradas-Ferreira P: Hydrogen peroxide-induced carbonylation of key metabolic enzymes in Saccharomyces cerevisiae: the involvement of the oxidative stress response regulators Yap1 and Skn7. Free Radic Biol Med 2002, 33:1507-1515.

29. Gomez-Pastor R, Perez-Torrado R, Cabiscol E, Matallana E: Transcriptomic and proteomic insights of the wine yeast biomass propagation process. FEMS Yeast Res 2010, 10:870-84.

30. Vignols F, Brehelin C, Surdin-Kerjan Y, Thomas D, Meyer Y: A yeast twohybrid knockout strain to explore thioredoxin-interacting proteins in vivo. Proc Natl Acad Sci USA 2005, 102:16729-16734.

31. Gomez-Pastor R, Perez-Torrado R, Matallana E: Modification of the TRX2 gene dose in Saccharomyces cerevisiae affects Hexokinase 2 gene regulation during wine yeast biomass production. Appl Microbiol Biotechnol 2011, (doi:10.1007/s00253-011-3738-9).

32. Yang K, Qiang D, Delaney S, Mehta R, Bruce WR, O'Brien PJ: Differences in glyoxal and methylglyoxal metabolism determine cellular susceptibility to protein carbonylation and cytotoxicity. Chem Biol Interact 2011, 191:322-329.

33. Park SG, Cha MK, Jeong W, Kim $\Perp H$ : Distinct physiological functions of thiol peroxidase isoenzymes in Saccharomyces cerevisiae. J Biol Chem 2000, 275:5723-5732.

34. Cabiscol E, Belli G, Tamarit J, Echave P, Herrero E, Ros J: Mitochondrial Hsp60, resistance to oxidative stress, and the labile iron pool are closely connected in Saccharomyces cerevisiae. J Biol Chem 2002, 277:44531-44538.

35. Jansen ML, Diderich JA, Mashego M, Hassane A, de Winde JH, DaranLapujade P: Prolonged selection in aerobic, glucose-limited chemostat cultures of Saccharomyces cerevisiae causes a partial loss of glycolytic capacity. Microbiology 2005, 151:1657-1669.

36. Gomez-Pastor R, Perez-Torrado R, Matallana E: Improving yield of industrial biomass propagation by increasing the Trx2p dosage. Bioeng Bugs 2010, 1:352-353

37. Chuang DM, Hough C, Senatorov W: Glyceraldehyde-3-phosphate dehydrogenase, apoptosis, and neurodegenerative diseases. Annu Rev Pharmacol Toxicol 2005, 45:269-290.

38. Ralser M, Wamelink MM, Kowald A, Gerisch B, Heeren G, Struys EA, Klipp E, Jakobs C, Breitenbach $M$, Lehrach $H$, Krobitsch S: Dynamic rerouting of the carbohydrate flux is key to counteracting oxidative stress. J Biol 2007, $6: 10$.

39. Grant $C M$ : Metabolic reconfiguration is a regulated response to oxidative stress. J Biol 2008, 7:1.

40. Reverter-Branch, Cabiscol E, Tamarit J, Sorolla MA, ngeles de la TM, Ros J: Chronological and replicative life-span extension in Saccharomyces cerevisiae by increased dosage of alcohol dehydrogenase 1. Microbiology 2007, 153:3667-3676.

41. Le MN, Clement G, Le MS, Tacnet F, Toledano MB: The Saccharomyces cerevisiae proteome of oxidized protein thiols: contrasted functions for the thioredoxin and glutathione pathways. J Biol Chem 2006, 281:10420-10430.

42. Michelet L, Zaffagnini M, Vanacker H, Le MP, Marchand C, Schroda M, Lemaire SD, Decottignies P: In vivo targets of S-thiolation in Chlamydomonas reinhardtii. J Biol Chem 2008, 283:21571-21578.

43. Ghezzi P: Regulation of protein function by glutathionylation. Free Radic Res 2005, 39:573-580.

44. Kumar A, Agarwal S, Heyman JA, Matson S, Heidtman M, Piccirillo S, Umansky L, Drawid A, Jansen R, Liu Y, Cheung KH, Miller P, Gerstein M, Roeder GS, Snyder M: Subcellular localization of the yeast proteome. Genes Dev 2002, 16:707-719.

45. Trotter EW, Grant CM: Overlapping roles of the cytoplasmic and mitochondrial redox regulatory systems in the yeast Saccharomyces cerevisiae. Eukaryot Cell 2005, 4:392-400.

46. Shringarpure R, Grune T, Mehlhase J, Davies KJ: Ubiquitin conjugation is not required for the degradation of oxidized proteins by proteasome. $J$ Biol Chem 2003, 278:311-318.

47. Maisonneuve E, Fraysse L, Lignon S, Capron L, Dukan S: Carbonylated proteins are detectable only in a degradation-resistant aggregate state in Escherichia coli. J Bacteriol 2008, 190:6609-6614.

48. Querol A, Barrio E, Huerta T, Ramon D: Molecular monitoring of wine fermentations conducted by active dry yeast strains. Appl Environ Microbiol 1992, 58:2948-2953.

49. Puig S, Ramon D, Perez-Ortin JE: Optimized method to obtain stable food-safe recombinant wine yeast strains. Journal of Agricultural and Food Chemistry 1998, 46:1689-1693. 
50. Gietz RD, Schiestl RH, Willems AR, Woods RA: Studies on the transformation of intact yeast cells by the LiAc/SS-DNA/PEG procedure. Yeast 1995, 11:355-360

51. Guldener U, Heck S, Fielder T, Beinhauer J, Hegemann JH: A new efficient gene disruption cassette for repeated use in budding yeast. Nucleic Acids Res 1996, 24:2519-2524.

52. Rodriguez-Porrata B, Novo M, Guillamon J, Rozes N, Mas A, Otero RC: Vitality enhancement of the rehydrated active dry wine yeast. Int I Food Microbiol 2008, 126:116-122.

53. Sorensen BK, Hojrup P, Ostergard E, Jorgensen CS, Enghild J, Ryder LR, Houen G: Silver staining of proteins on electroblotting membranes and intensification of silver staining of proteins separated by polyacrylamide gel electrophoresis. Anal Biochem 2002, 304:33-41.

54. Blandino A, Caro I, Cantero D: Comparative study of alcohol dehydrogenase activity in flor yeast extracts. Biotech Letters 1997, 19:651-654.

55. Maitra PK, Lobo Z: A kinetic study of glycolytic enzyme synthesis in yeast. J Biol Chem 1971, 246:475-488.

56. Flikweert MT, Van Der ZL, Janssen WM, Steensma HY, Van Dijken JP, Pronk JT: Pyruvate decarboxylase: an indispensable enzyme for growth of Saccharomyces cerevisiae on glucose. Yeast 1996, 12:247-257.

57. Jakubowski W, Bilinski T, Bartosz G: Oxidative stress during aging of stationary cultures of the yeast Saccharomyces cerevisiae. Free Radic Biol Med 2000, 28:659-664.

doi:10.1186/1475-2859-11-4

Cite this article as: Gómez-Pastor et al:: Engineered Trx2p industrial yeast strain protects glycolysis and fermentation proteins from oxidative carbonylation during biomass propagation. Microbial Cell Factories 2012 11:4.

\section{Submit your next manuscript to BioMed Central} and take full advantage of:

- Convenient online submission

- Thorough peer review

- No space constraints or color figure charges

- Immediate publication on acceptance

- Inclusion in PubMed, CAS, Scopus and Google Scholar

- Research which is freely available for redistribution

Submit your manuscript at www.biomedcentral.com/submit 